\title{
Cognitive capital: the case for a construct
}

\author{
John Bynner \\ Institute of Education, London \\ Michael Wadsworth \\ Honorary Senior Scientist, MRC Unit for Lifelong Health and Ageing \\ J.Bynner@ioe.ac.uk
}

This Special Issue confirms the value of working across birth cohorts in the investigation of a key theoretical construct in child and adult development. From what was a very compressed analysis programme to support a seminar series,' the papers presented here are not only highly informative and challenging in their own terms, but provide the foundations of continuing research. We start with terminology then move to research findings and the methodological issues they raise. Conclusions follow and next research steps.

\section{Concepts and measures}

The terms 'cognitive function', 'cognition', 'intelligence', 'cognitive ability', 'cognitive capital', "cognitive capability' and 'cognitive reserve' are distinctive, but as is clear from their use in the papers in this Special Issue, they overlap. Moreover with the exception of Richards and Deary's introductory paper on cognitive capital in the British birth cohorts (this issue) and Richards, Stephen and Mishra's paper (this issue) on health returns to cognitive capital, none make any specific reference to cognitive capital as such. They are, however, implicitly working with the idea in the analyses they report. The seminar series, of which the papers formed a part, served a valuable purpose in highlighting some of the ambiguities in conceptualisation and terminology common in this area (Lerner 2002). The seminars also demonstrated the value of longitudinal data collected from birth cohorts starting at different times, in helping to illuminate the defining features of cognitive capital and its uses.
The key term where problems arise is that of cognitive ability, almost synonymous with, but still distinct from, intelligence. The former has The connotations of a personal attribute identified with performance, particularly on cognitive tests. Traditionally, exploratory factor analysis, and more recently, structural equation modelling, have been used to identify and operationalise the deeper ('latent') construct of Intelligence - also referred to as ' $G$ '. There is, as Richards and Deary make clear, a long tradition in psychology stemming back to the work of Galton (1869) and Spearman (1927) that seeks a biological basis for such a variable, either in single or multiple forms. This is less the case for cognitive ability, cognitive capability and especially cognitive capital and its associated outcomes in examination performance and qualifications, where the focus moves along the continuum from physiology to the learned attributes through which cognitive development is manifest. At this stage, cognitive capital can be usefully conceptualised as an accumulating asset derived from those aspects of cognitive functioning concerned with such developing faculties as memory, attention, perception, problem solving and mental imagery which can be drawn upon to create, and take advantage of, opportunities to sustain wellbeing in response to environmental challenge and stress (Henry 2004).

Notably, Schoon (this issue) operationalises the latent variable ' $G$ ' by means of two measures of verbal and non-verbal ability collected at age 10/11 in the 1946 cohort study, a single measure comprising these two components, in the 1958 study, and selected 
British Ability Scales in the 1970 study. Her identification and measure of ' $G$ ', is validated by structural equation modelling. The measurement of intelligence is sometimes achieved in this way, or directly from one test of reasoning such as Raven's' Progressive Matrices or the Stanford-Binet Intelligence test, or again, in line with Schoon's approach, for the 1970 cohort study, by assessment from a set of skills or abilities such as the British Ability Scales from which 'general ability' (G) or intelligence (IQ) can be derived.

The biological basis of $I Q$ is where controversy has raged, principally about the extent of its heritability or genetic origins. Richards and Deary (this issue) refer to 30 per cent of the variance that can be accounted for genetically from ability tests, free of the learning involved in the acquisition of educational skills of the reading and maths kind. They also point to a cohort shift revealing much less stability in performance on cognitive tests than was originally thought. Moreover, survey evidence across the across the world suggests that average levels of IQ test performance are rising (Arbuckle et al 1998; Emanuelson and Svenson 1990; Wadsworth 1991; Flynn 1987, 1999) pointing to the impact of education in stimulating cognitive development.

It is notable that the expectations of Galton and his followers, that genetically based $G$ would be manifested in measures of psychophysical attributes such as reaction time and visual acuity, correlated with each other and with educational success, failed to be borne out. It was not until cognitive skills of central important in education such as verbal reasoning, were used at the beginning of the $19^{\text {th }}$ century in France in the design of the Binet-Simon intelligence test, and validated by educational performance as assessed by teachers, that the expected correlations were established (Richardson and Bynner 1984).

Nevertheless when it comes to practical value and use in education in particular, teachers will typically tend to hold to the idea that ability, as measured by tests, in some way defines a genetic endowment effect which sets limits on what a child is capable of doing educationally, and this in turn tends to downplay the extent to which modifications are possible (c.f. Caspi et al 1996). We might say that the traditionally divided English school system based on levels of ability - e.g. Grammar, Technical and Secondary Modern was founded on such an understanding of the limitations on cognitive development.

In contrast, the cognitive capital conception stresses the importance of supplying continuing open learning opportunities to enhance ability throughout life. This is, of course, given the right learning conditions and the individual motivation to take advantage of them with the help of an effective teacher and strong family support (Douglas 1964; Werner 1989; Pilling 1990). Such effectiveness is hampered by the material conditions of children's lives. Sutherland shows in her paper 'Setting the Scene' (this issue) how these improved radically as wartime receded, and how government investment to match employer demands expanded education opportunities on a massive scale. Partly in response to the changing labour market and the take up of education in response, the class structure also shifted, with the declining manual working class jobs giving way to the expanding white collar and professional jobs that formed the middle class.

The British birth cohort studies starting in 1946 reflected these changes. For example, pre-school educational provision was meagre in the early post-war years, parental education was poor and nutrition was controlled by food rationing. Opportunities in further and higher education, and consequently in occupation and earnings, were limited (also see Blane; Wadsworth, this issue). By the 1970s, when the third study began, all these influential circumstances had changed, as reported in "Changing Britain, Changing Lives", which compares the members of the first three birth cohorts' situations in their early 30s (Ferri, Bynner and Wadsworth 2003). In the most recent studies - the Avon Longitudinal Study of Parents and Children (ALSPAC), begun in 19911992, and the Millennium birth cohort study begun in 2000-2001 - the shifts have continued, though not on quite the same scale or in quite the same form as in the earlier studies.

Cognitive capital in line with other forms of non-monetary capital - human capital, social 
capital, emotional capital - is thus an asset to be acquired rather than a fixed attribute embedded in the human organism at conception. Describing such an asset, arising from cognitive functioning, as 'capital' has important and illuminating connotations missing from the psychologists' alternative, ' $G$ '.

As a form of 'capital', cognitive capital meets the requirements of that term (Schuller, Bynner and Feinstein 2004). It is invested, e.g. in educational attainment through the efforts, initially, of parents and subsequently by children themselves. It is also transferable from teacher to learner and contributes to stocks that have value such as qualifications in the labour market. It is also fungible, that is to say one form of cognitive capital can be transformed into another, e.g. cognitive into human or social capital. It is distributed unequally in the general population and it generates educational returns in terms of educability, employability, earnings, health and citizenship. This is not to say that there is no biological component in the attributes involved in accumulating it, simply that the emphasis on capital growth and deployment of capital to produce rewards may be seen as offering a more tangible construct in life course terms, than notions of "fixed" ability and "intelligence".

The idea of ability separable and prior to attainment appeals to many researchers, of which economists are a notable example, because it offers the possibility of an exogenous variable, i.e. rooted in genetic endowment, that can be conditioned out of the relationship between say, exposure to different curricula and outcomes in terms of earnings. Such an assumption is implicit in Schoon, Schoon and Duckworth, Schoon and colleagues' and Richards, Stephen and Mishra's papers (this issue). Economists Gregg and Macmillan (this issue) are in this case the exception in using early measures of cognitive ability in the more recent child cohorts as the best approximation to educational attainment as revealed by qualifications. The attraction of Schoon's use of structural equation modelling (this issue) is that it not only controls for, but uses for explanatory purposes, the endogeneity that economists particularly want to remove.
Richards, Stephen and Mishra deploy similar reasoning from previous research, based on the earliest cohorts and their own research, using 1946 cohort study data, to identify the importance of educational achievement as a predictor of good health and resistance to cognitive and physical decline in old age.

The seminar series started with concepts and usage in education, then moved sequentially through the different stages of life, concluding finally with overall appraisal and next steps. The different papers add significantly to our understanding of the changing nature of cognitive capital both with age and across time. What does the stage by stage analysis tell us?

\section{Early years}

Schoon and colleagues (this issue) use the Millennium Cohort Study, with data collected up to age 3 , to show that the experience of maternal stress in the first two years of life disrupts good parent/child relations. These are central to the foundations of cognitive development as reflected in 'school readiness'. The relationship between economic conditions and cognitive outcomes has been long established and continues (e.g. Feinstein 2004). It may in part be by maternal stress resulting from original hardship. Prolonged experience of stressful conditions in childhood can disrupt physical growth (Widdowson 1951; Montgomery et al 1997). The important contribution here from Schoon et al is to show that, taking account of economic conditions, parental stress adds to, rather than removes, the problems infants have in acquiring cognitive skills such as word recognition and number concepts. Economic hardship does not account wholly for the critical effect of parental stress, which itself is influenced by poverty; rather there is a direct and indirect connection between economic conditions and children's cognitive outcomes. Notably, the pathways are slightly different for behavioural adjustment outcomes where the relationship with maternal stress is stronger, than with cognitive development. 


\section{From childhood to adolescence}

In Duckworth and Schoon's paper (this issue) on the role of cognitive skills and selfregulation in educational progress through primary school, the focus shifts from the parental effect on children's cognitive growth, as reflected in maternal stress, to the child's developing non-cognitive attributes. Their analysis of the rich ALSPAC data, collected annually from birth to fourteen, shows the important role of 'inattention' and 'external locus of control', less so 'poor self-esteem', in impeding the acquisition of cognitive skills. They also find a weakening of the effects of family circumstances by the end of primary school in some groups. It seems that family circumstances are critically important at the earliest stages of life in predicting cognitive performance later on. Such an effect becomes less apparent with age, as the whole psychological make-up of the individual, including cognitive function, and the impact of the wider social environment on that make-up, begin to take more permanent shape. In cognitive capital terms, the research also suggests that educational attainment - more typically described in the early years as educational ability - gains from a combination of factors of which the cognitive component is only one of many that enable individual children to 'buck the trend'. In other words non-cognitive factors, of which attention is the prime example, are revealed as increasingly important in educational attainment, not least because these attributes chime in with the 'hidden school curriculum' concerned with personal and social development.

\section{Adolescence to adulthood}

In the following paper (Schoon, this issue) the focus shifts again, this time to the impact of the social and policy context on the whole educational trajectory up to adulthood (age 26) via the examination of the accumulation of cognitive capital across the 1946, 1958 and 1970 birth cohorts. The notable finding here, in line with earlier structural equation modelling of 1958 and 1970 cohort data (Bynner 1998), is that from the earlier to the later cohorts there is a declining effect of family social class on cognitive development, as a range of other factors, non-cognitive and social, play an increasing part in determining the long-term outcome. Importantly, an improvement in educational participation and a reducing gender gap in attainment are also shown.

Schoon's analysis reveals very well the challenges to be met in this kind of crosscohort comparison because of the changing forms of measurement, both within cohorts to reflect age differences, but particularly across them. Strong assumptions are needed to be sure that we are in fact comparing like with like, which the latent variable approach through structural equation modelling that she employs, can resolve only to a limited extent. The paper displays excellent applications of validation approaches in assuring us that comparisons are legitimate. But as with every other use of evidence of this kind the analysis cannot stand entirely alone. It needs to be continually reinforced through triangulation with evidence from other sources and the evolving policy framework as discussed in Sutherland's paper (this issue), where reducing educational inequalities is a dominant theme. The more cognitive capital becomes detached from social class, for example, the more we can become convinced that policy has moved in the direction of enhancing social mobility and the more important it becomes at the same time to reduce educational inequality. Policy makers and practitioners need to be constantly aware that other attributes are also playing a part in the production of such mobility and inequality, and are also critically important in determining their outcomes.

\section{Income and Qualifications}

The most ambitious cross-cohort analysis is that from Gregg and Macmillan (this issue) in their investigation of the impact of family income on cognitive ability and educational attainment. Educational attainment is assessed through standard educational attainment tests for the most recent cohorts, together with English public examinations - GCE, O Levels, A Levels and university degrees for the earlier ones. They use not only the 1946, 1958 and 1970 birth cohorts for the investigation, but also the British Household Panel Study - Waves 1, 2, 3 for which ability tests are used as surrogates for educational attainment tests and the Longitudinal Study of Young People in 
England (LSYPE), where such tests are also used alongside qualifications. They show that equality of opportunity and outcomes in educational attainment increased across successive cohorts. They also demonstrate again the weakening relationship of family income to achievement across successive cohorts and when earlier socio-economic circumstances and educational performance (and cognitive ability) data are taken into account.

Validation of the measures used is another important feature of their paper, with comprehensive robustness checks applied across cohorts for the income measures used and assessment of biases due to sample attrition in the longitudinal surveys. The latter shows remarkably good maintenance of representativeness of the samples involved.

\section{Beginnings of cognitive decline}

Finally we move to mid-life functioning and the risk factors for the diseases of old age where Richards, Stephen and Mishra (this issue) using the 1946 cohort study, whose members are now in their mid-60s, investigate the relationship between cognitive capital and health outcomes. They make the useful distinction between on the one hand, the protective value of early cognitive functioning in relation to degenerative diseases of the nervous system such as Alzheimer's where the physiological components help to build 'cognitive reserve' and on the other, cognitive capital, as assessed by ability tests, which is linked more closely to such health outcomes as cardiovascular disease risk. Their main focus is on the latter, demonstrating that cognitive ability relates specifically to a range of physical conditions predicting risk of cardiovascular disease: smoking, physical exercise, unhealthy dietary choice, obesity, hypertension and noninsulin dependent diabetes. They also show that the long-term effect of cognitive capital, as measured by cognitive ability (IQ) tests, in moderating these risk factors is mediated by educational achievement.

\section{Conclusion}

The analyses answer some questions about the significance of cognitive capital in life course construction but leave many issues still to be resolved. Elucidating the role of biological (including genetic) factors in cognitive functioning and development continues to be a challenge, as does the impact of changing policy frameworks on their realisation through the growth of cognitive capital as a factor in achievement in all spheres of life. The development of further methods for assuring equivalence and robustness of the measures used, and for assessing and compensating for, by means of weighting and such methods as multiple imputation attrition bias, are other areas where significant research advance is needed. Appreciating fully the limitations of the cohort study data in cross-cohort analysis, and how to optimise their potential for work of this kind, requires a much more extended period of screening, testing and new variable construction than was possible for the research reported on this issue. The analyses were all completed in a relatively short period of time to meet the demands of a seminar timetable; hence the necessary test evaluation and variable development and data adjustment prior to analysis could be undertaken only to a limited extent.

Such work in future will inform not only existing analyses but particularly those to come, using the new data due to be collected in the earlier studies and especially in the relatively new studies, such as the Millennium cohort study and the prospective new birth cohort study due to begin in 2012. This latter study is expected to embrace a range of additional dimensions for understanding early cognitive functioning, its conversion into cognitive capital and its realisation through later beneficial outcomes. These dimensions include the relational factors in families that enhance or impede the development of such functions and also in the community via social settings such as the peer group. The relational inputs into child development raise further questions about the ecological impact of the local physical and social environment, which requires the development of a multi-level framework for analysis - from local education authority to the school, the community and the family.

The papers reinforce the case for cognitive capital as embracing those attributes associated with cognitive functioning, which are central to cognitive capacity and adaptive capability in later life. Such functioning is observable early on in life and the faculties it embraces - including, memory, attention, problem solving and mental imagery as 
assessed by tests - continue to develop through adolescence and adulthood, before levelling-off and starting to decline in old age. Their significance in educational performance extends further to life chances in relation to occupation and income, health and wellbeing, and functioning more generally, during the working years. The demonstrated protective value of cognitive capital through the medium of cognitive reserve also makes the case for investment in continuing adult learning and effective health education through to old age, as a form of resistance to cognitive decline (Richards and Deary 2005).

On a more technical front, the papers also show that the tasks of the kind deployed by psychologists in diagnostic ability tests, also tapping into intelligence, are little different in most respects from elements of the standard attainment tests, which measure educational outcomes at various educational stages. Viewing these test performances in terms of accumulating cognitive capital, identifies them more closely with 'educational progress' and the foundations of educational capability - that is to say the educational competences needed to achieve personal and community goals (Sen 1992). In contrast, traditional conceptions of intelligence, as measured by ability tests, have tended to see it as rooted in the relatively fixed biological nature of the individual, comparable more to height than an accumulating capital resource. In heurist and practical terms, there is much to be said for a term that reflects more fully the dynamics of life course development, and the exercise of human agency in a social context.

The papers also show the potential of the valuable national resource of the birth cohort and other large-scale longitudinal studies, for both policy and academic research. Their value lies not only in their wide-ranging data over many years of life, but also in their location in different historical periods (Wadsworth and Bynner, in press). This latter characteristic makes it possible to allow not only for policy change, but also for the changing effects of aspirations and expectations among children and by parents and society for children, from the pre-school years onwards.
The papers suggest the need for a review of longitudinal data resources in two areas in particular: the aim would be to discover new resources and synthesize findings so that researchers in this cross-disciplinary area can better understand how to design innovative research. First, is a review of childhood studies that have the capacity to support the investigation of influences on the pre-school development of cognitive capital, including physical growth, and of such self regulation skills as attention, patience, persistence, and impulsivity and their relationship with the family's socio-economic and material circumstances. The second area suggested for review is of studies that yield data comparable with the data used in the papers in this issue, but which have been undertaken in other cultures, with different expectations, aspirations and policies for children. The Scandinavian countries and the US and Canada and New Zealand are, in the short- term, the most likely sources. The expansion of birth cohort studies across the world since the millennium points in time to much wider intercultural research potential.

The inter-cohort analyses presented here are a stimulus for further work. Whilst the direction of new work concerning the equity of changing opportunities is evident, some new directions in the study of outcomes might be appropriate. The nature and effects of parenting by members of the birth cohorts, and in particular their aspirations for their children and their educational choices, can be studied intergenerationally in the 1946, 1958 and 1970 cohorts, using existing data collected on the next generation. In addition, the range of adult outcomes studied could be expanded in three types of area.

First, new studies, comparing across cohorts the nature of adult life for individuals, should be concerned with perceived quality of life outcomes, such as health and well-being and fulfilment in relation to life course goals and how these change with age. A second area of outcomes that could usefully be investigated includes indicators of occupational skills - that is to say, the ways in which high skill levels, intellectual, creative and practical, build upon 
the cognitive capital acquired earlier. Research would also include important questions about the role in the acquisition of these skills of biological aspects of early cognitive functioning and development. A third area of outcome indicators concerns the changing skills requirements of the labour market in relation to the skills acquired by members of the cohorts. The question to be asked is how far the attained skill levels matched labour market needs at specific times, and the role cognitive capital played in facilitating such a match.

The suggested programme is challenging but likely to be rewarding because of the combination of new conceptualisation with ideally targeted research resources for undertaking it. The authors of the papers in this Special Issue are to be commended for their contribution to signposting the way forward.

\section{References}

Arbuckle TA, Maag U, Pushkar D, and Chaikelson JS. (1998) Individual differences in trajectory of intellectual development over 45 years of adulthood. Psychology and Aging, 13, 663-75.

Bynner J. (1998) Education and family components of identity in the transition from school to work. International Journal of Behavioural Development, 22, 29-53.

Caspi A, Harkeness AR, Moffitt TE and Silver PA. (1996) Intellectual performance: continuity and change, in PA Silver and WR Stanton (eds.) Child to Adult. pp 59-74, Oxford University Press, Oxford.

Douglas JWB. (1964) The Home and the School, MacGibbon Kee, London.

Duckworth K and Schoon I. (2010) Progress and attainment during primary school: the roles of literacy, numeracy and self-regulation. Longitudinal and Life Course Studies 1, 223-240.

Emanuelson I and Svensson A. (1990) Changes in Intelligence over a Quarter of a Century. Scandinavian Journal of Educational Research, 34, 171-187.

Feinstein L. (2004) Mobility in children's cognitive development during school life. Oxford Review of Economic Policy, 20, 213-229.

Ferri E, Bynner J, and Wadsworth M. (eds) (2003) Changing Britain, changing lives: three generations at the end of the century. Institute of Education Press, London.

Flynn JR. (1987) Massive IQ gains in 14 nations: what IQ tests really measure. Psychological Bulletin, 95, 29-51.

Flynn JR. (1999) Searching for justice: the discovery of IQ gains over time. American Psychologist, 54. 5-20.

Galton F. (1869) Hereditary Genius: an enquiry into its laws and consequences. Macmillan, London.

Gregg P and Macmillan L. (2010) Family income, education and cognitive ability in the next generation: exploring income gradients in education and test scores for current cohorts of youth. Longitudinal and Life Course Studies 1, 259-280.

Henry P. (2004) Hope, hopelessness, and coping: a framework for class-distinctive cognitive capital. Psychology and Marketing, 21, 375-403.Lerner RM (2002) Concepts and Theories of Human Development. (Third edition). Lawrence Erlbaum, New Jersey.

Lerner R. ( 2002) Concepts and theories of Human Development ( $3^{\text {rd }}$ Edition). Lawrence Erlbaum Associates, Mahwah New Jersey.

Montgomery SM, Bartley MJ and Wilkinson RG. (1997) Family conflict and slow growth. Archives of Disease in Childhood, 77, 326-330.

Pilling D. (1990) Escape from Disadvantage. The Falmer Press, London.

Richards $M$ and Deary IJ. (2005) A life course approach to cognitive reserve: a model for cognitive aging and development? Annals of Neurology, 58, 617-22.

Richards M and Deary IJ. (2010) Cognitive capital in the British birth cohorts: an introduction. Longitudinal and Life Course Studies, 1, 197-200.

Richards M, Stephen A and Mishra G. (2010) Health returns to cognitive capital in the British 1946 birth cohort.

Richardson K and Bynner JM. (1984) Intelligence: Past and future. International Journal of Psychology, 19, 499-526.

Schoon I. (2010) Childhood cognitive ability and adult academic attainment: evidence from three British cohort studies. Longitudinal and Life Course Studies 1, 241-258.

Schoon I, Hope S, Ross A and Duckworth K. (2010) Family hardship and children's development: the early years. Longitudinal and Life Course Studies 1, 209-222. 
Schuller T, Bynner J and Feinstein L. (2004) Capitals and Capabilities, Research Centre for the Wider Benefits of Learning. Discussion Paper No1 http://www.learningbenefits.net/

Sen A. (1992) Inequality Re-examined. Clarendon Press, Oxford.

Spearman, C. (1927) The Abilities of Man. Macmillan, London.

Sutherland G. (2010) Setting the scene. Longitudinal and Life Course Studies 1, 201-208.

Wadsworth MEJ. (1991) The Imprint of Time; childhood, history, and adult life. Clarendon Press, Oxford.

Wadsworth MEJ, and Bynner J. (in press) A companion to life course studies: the social and historical context of the British birth cohort studies. Routledge, London.

Werner EE. (1989) Vulnerability and resiliency: a longitudinal perspective. In M

Brambring, F Lösel and H Skowronek (eds.) Children at Risk: Assessment, Longitudinal Research and Intervention. Walter de Gruyter, Berlin.

Widdowson EM. (1951) Mental contentment and physical growth. Lancet, I, 1316-1318.

\section{Endnotes}

i Supported by the Nuffield Foundation 